\title{
VAPOR CORE TURBULENCE IN ANNULAR TWO-PHASE FLOW
}

$$
\text { CONF-990702-- }
$$

T.A.Trabold, R. Kumar

June 1998

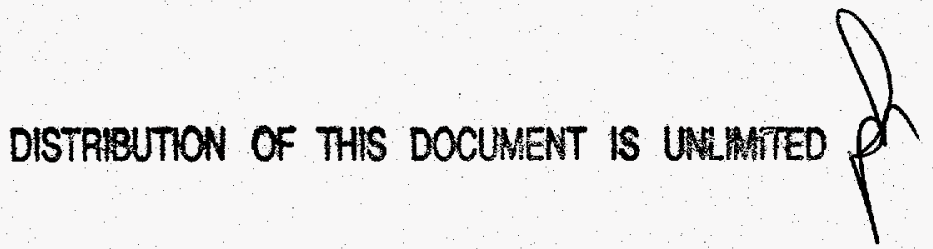
MASTER

\section{NOTICE}

This report was prepared as an account of work sponsored by the United States Government. Neither the United States, nor the United States Department of Energy, nor any of their employees, nor any of their contractors, subcontractors, or their employees, makes any warranty, express or implied, or assumes any legal liability or responsibility for the accuracy, completeness or usefulness of any information, apparatus, product or process disclosed, or represents that its use would not infringe privately owned rights. 


\section{DISCLAIMER}

This report was prepared as an account of work sponsored by an agency of the United States Government. Neither the United States Government nor any agency thereof, nor any of their employees, make any warranty, express or implied, or assumes any legal liability or responsibility for the accuracy, completeness, or usefulness of any information, apparatus, product, or process disclosed, or represents that its use would not infringe privately owned rights. Reference herein to any specific commercial product, process, or service by trade name, trademark, manufacturer, or otherwise does not necessarily constitute or imply its endorsement, recommendation, or favoring by the United States Government or any agency thereof. The views and opinions of authors expressed herein do not necessar. ily state or reflect those of the United States Government or any agency thereof. 


\section{DISCLAIMER}

Portions of this document may be illegible in electronic image products. Images are produced from the best available original document. 
Vapor Core Turbulence in Annular Two-Phase Flow

Thomas A. Trabold and Ranganathan Kumar

Lockheed Martin Corporation

P.O. Box 1072

Schenectady, NY 12309 


\section{Nomenclature}

$B \quad$ bias

$D_{h} \quad$ duct hydraulic diameter

$d_{d} \quad$ droplet diameter

$d_{s}$. HFA probe sensor spacing

$d_{s m} \quad$ Sauter mean droplet diameter

$E(\tau)$ cross-correlation factor

$f_{d} \quad$ droplet frequency

$G$ mass flux

$j \quad$ superficial velocity

$L \quad$ test section length

$P \quad$ pressure

$Q \quad$ volumetric flow rate

$S_{\bar{x}} \quad$ precision index

$t \quad$ duct thickness

$t_{95}$ student's $t$ for $95 \%$ confidence

$U$ measurement uncertainty

$V \quad$ HFA output voltage

$V_{\min }$ minimum voltage in HFA voltage histogram

$V_{\text {peak }}$ peak voltage in HFA voltage histogram

$V_{d} \quad$ droplet velocity

$V_{i} \quad$ interfacial velocity

$V_{m} \quad$ mixture velocity

$V_{T} \quad$ threshold voltage for HFA probe signal analysis

$W \quad$ duct width

$w \quad$ mass flow rate

$X \quad$ streamwise (length) dimension

$Y \quad$ transverse (width) dimension

$Z \quad$ spacing (thickness) dimension

Greek Symbols

$\alpha \quad$ void fraction

$\rho$ density

$\tau_{\mathrm{m}} \quad$ time associated with maximum cross-correlation factor

Subscripts

$d \quad$ droplet

$g \quad$ gas phase

$l \quad$ liquid phase

$2 \phi$ two-phase (mixture) 


\begin{abstract}
This paper reports a new technique to measure vapor turbulence in two-phase fiows using hot-film anemometry. Continuous vapor turbulence measurements along with local void fraction, droplet frequency, droplet velocity and droplet diameter were measured in a thin, vertical duct. By first eliminating the portion of the output voltage signal resulting from the interaction of dispersed liquid droplets with the HFA sensor, the discrete voltage samples associated with the vapor phase were separately analyzed. The data revealed that, over the range of liquid droplet sizes and concentrations encountered, the presence of the droplet field acts to enhance vapor turbulence. In addition, there is evidence that vapor turbulence is significantly influenced by the wall-bounded liquid film. The present results are qualitatively consistent with the limited data available in the open literature.
\end{abstract}




\section{Introduction}

In two-phase annular flow, the liquid phase flows in part as a film along the walls and partly as droplets entrained in the central gas core. The ratio of the liquid phase in the film to that in droplet form varies according to the fluid flow rates and the gas-liquid density ratio. The interface between the liquid film and the gas core is characterized by disturbance waves with heights which can be several times larger than the mean film thickness. Also, these waves can travel at velocities much greater than that of the liquid film. At high gas velocities, the disturbance wave crests are sheared off, causing the entrainment of droplets into a highly turbulent vapor core. Another mechanism by which droplets can be formed is by the disintegration of the liquid bridges in the churn-turbulent regime. The droplets thus formed are transferred and redeposited on the film. Even in adiabatic systems, such droplet transfer from and to the liquid film is not in equilibrium, and it has been noted that the droplet flow rate in the core increases along the length of the duct (Ueda, 1979).

Physically based models for annular two-phase flows account for the split of the liquid and vapor phases between continuous and dispersed fields. Closure of these models requires knowledge of the turbulence characteristics of the continuous vapor phase which is modified due to the presence of the droplet field. Vapor core turbulence is known to influence interfacial shear, and affect the transport and structure of the dispersed liquid droplet field, and ultimately the droplet entrainment and deposition processes.

Development of realistic two-phase turbulence models depends heavily on the availability of pertinent experimental data. A significant body of experimental data exists for dispersed solid or liquid particles transported in jet and duct flows. The review paper by Hetsroni (1989) examines the effect of different size particles on energy-containing eddies. Using the gas-solid 
data of Tsuji et al. (1982, 1984), Lee and Durst (1982), and other data obtained in jets and liquidsolid flows, Hetstroni showed that particles with a Reynolds number of less than 400 tended to suppress the turbulence. Particles with a Reynolds number of larger than 400 enhanced turbulence, possibly due to vortex shedding. None of these studies dealt with the effect of a liquid film adhering to the wall in annular flow. Only one study has reported vapor turbulence measurements in air-water annular flows with a liquid film interface (Azzopardi and Teixeira, 1994b). They concluded that turbulence intensities were higher than the values that would normally be found in a pipe with a wall roughness equivalent to that of the film interface. No known vapor turbulence measurements are available in the literature for refrigerant flows in the presence of an interface. The lack of such data stems from the complexity of conducting experiments in annular flows, in which the presence of a wall-bounded liquid film often precludes the use of well established measurement methods. In addition to the scarcity of turbulence data in annular flow, the majority of the material in the open literature on annular flows involves circular tubes.

Hot-film anemometry (HFA) techniques have been used extensively for local turbulence measurements in both bubbly flow (Serizawa et al., 1975; Michiyoshi and Serizawa, 1986; Wang et al., 1990; Lance and Bataille, 1991; Hogsett and Ishii, 1997) and droplet/particle flows (Ginzburg, 1971; Hetsroni and Sokolov, 1971). These measurements have been criticized in favor of those acquired with the nonintrusive laser Doppler velocimeter (LDV) method. Faeth (1983; 1987) contended that in applying the HFA technique, only a relatively small fraction of the dispersed phase volumes impact the hot-film sensor, thereby biasing the measurements of fluctuating velocity attributed to the continuous phase. However, several authors (e.g., Franz et al., 1984; Suzanne et al., 1997) demonstrated in bubbly flow that simultaneous LDV and HFA 
measurements of mean liquid velocity are in very close agreement. Moreover, in the work of Suzanne et al., it was clearly shown that the two techniques lead to the same results, with less than $5 \%$ difference in moments up to sixth order at low void fraction, provided correct signal processing is applied. Based on this literature, the HFA technique can provide accurate measurement of continuous phase turbulence intensity, in particular when the local volume fraction of the dispersed phase is low.

The specific objectives of the present study are to: a) extend the established hot-film anemometer technique for turbulence measurements in refrigerant flows using a dual-sensor probe, b) perform drop size and turbulence measurements in the vapor core at gas-liquid density ratios comparable to steam-water at high pressure, and c) provide insight into the complex physical phenomena characteristic of turbulent, annular two-phase flows.

\section{Experimental Methods}

\section{Test Facility and Procedure:}

The working fluid for all experiments was the nonchlorinated refrigerant fluid 1,1,1,2tetrafluoroethane (R-134a). Key components of the experimental loop are a chiller and a pressurizer to maintain the liquid phase at the inlet of the circulating canned rotor pump, a large $\mathrm{CO}_{2}$ heat exchanger, high/low range throttle valves, flow meters, and a narrow vertical test section. The test section given in Figure 1 has a length of $1.2 \mathrm{~m}$ and a hydraulic diameter of 4.85 $\mathrm{mm}$ with a cross-section aspect ratio of approximately 20 (Figure 1). Loop conditions are set by programmed logic controllers. Loop data include mass flow, temperature, pressure, heater power, and incremental pressure drop. The two-phase flow is established by means of heaters in the inlet flow stream. The main instrumentation system used in the test loop is comprised of a hot-film anemometer, a laser Doppler velocimeter (for droplet velocity) and a gamma densitometer (for void fraction). Data from the latter two instruments are not provided in this paper and therefore, 
these instruments will not be described here; details are provided in Trabold et al. (1998). Adiabatic flows in the test section were established by using a heater located upstream of the test section, and raising its power until the specified average void fraction (as measured by the gamma densitometer) was reached at $\mathrm{X} / \mathrm{L}=0.68$.

\section{Hot Film Anemometry}

Hot-film anemometry (HFA) is an established technique for measurement of local parameters in two-phase flow, and its use in various refrigerant fluid experiments has been reported previously (Trabold et al., 1994; 1997; 1998). The constant temperature hot-film anemometer consists of a probe which is directly exposed to the two-phase flow field, and electronic circuitry which controls the amount of current supplied to the probe. When fluid passes the probe, the film sensor of the anemometer is cooled, which decreases the sensors's resistance. An amplifier in the resistive bridge circuit instantaneously increases the current through the sensor to maintain it at a constant temperature. Since the cooling capacities of the vapor and liquid in a two-phase mixture are quite different, a distinct change in the voltage signal is observed depending on which phase envelops the hot-film at any instant in time.

As illustrated in Figure 2, the hot-film probe is comprised of two active sensors which are separated in the streamwise dimension by a known distance in the range of 1.2 to $2.5 \mathrm{~mm}$. The sensitive element of the sensor is comprised of a thin layer of platinum deposited on a small quartz fiber which is suspended by two narrow needles. The active portion of the platinum layer is $25 \mu \mathrm{m}$ in diameter and $254 \mu \mathrm{m}$ long. For void fraction and frequency measurements, a single sensor is adequate and the lower upstream sensor is used to obtain these data. The use of two sensors permits acquisition of interfacial velocity measurements based on the cross-correlations between two output voltage signals. The peak in the cross-correlation vs. time plot corresponds to the most probable time required for a gas-liquid interface to travel between the sensors, from which the mean interfacial velocity can be calculated. For the reported experiments, the test 
section is fitted with an HFA probe at $X / D_{h}=182$ (i.e., $X / L=0.73$ ) to pass through the quartz windows, and position the probe to scan across the spacing $(\mathrm{Z})$ dimension. The HFA probe is fixed to a small traversing mechanism which enables fine movement with $1 \mu \mathrm{m}$ accuracy. The closest the HFA sensor can be precisely positioned from the test section wall is $0.15 \mathrm{~mm}$. From this location, void fraction, droplet frequency, droplet velocity, droplet diameter and vapor turbulence profiles were measured up to the center of the test section $Z$ dimension. Details of these measurement techniques are provided below.

The analog-to-digital converter produces a digital record of the HFA voltage signal which can be analyzed to provide a measurement of the local void fraction. As illustrated in Figure 3, a characteristic continuous vapor and dispersed liquid signal is comprised of a fairly constant baseline voltage level with periodic positive pulses indicative of liquid droplets impacting the probe sensor. The rapid voltage rise observed upon impact of the front droplet interface is due to the cooling of the sensor element which decreases its resistance. An amplifier in the resistive bridge circuit increases the current through the sensor to maintain it at a constant temperature. The subsequent voltage decrease, which tends to be somewhat slower, is due to the heating of the droplet and penetration of the rear droplet interface. Previous researchers (e.g., Goldschmidt and Householder, 1969; Mahler and Mangus, 1984) observed for dispersed liquid experiments with water and oil that the droplets adhere to the HFA sensor element, heat up, and then evaporate. For R134a droplets, it is considered unlikely that the same process occurs since the surface tension is lower and the motion of droplets above a certain critical size is not significantly impeded. The close agreement between droplet velocities obtained with the HFA probe via cross-correlation and the nonintrusive laser Doppler velocimetry technique (Trabold et al., 1998) supports this interpretation. Also, the droplet heating process is not as significant when the droplets are at or near the saturation temperature.

The combined slope and level thresholding method of Carvalho and Bergles (1992) was used to analyze the HFA output voltage signals for determination of local vapor volume fraction. The voltage histogram associated with a dispersed liquid/continuous vapor waveform (Figure 3 ) is 
shown in Figure 4. The large peak represents the baseline vapor phase voltage. Samples in voltage bins to the right of this peak correspond to discrete samples of the liquid droplet pulses. Depending on the magnitude of the dispersed liquid volume fraction, a smaller liquid phase peak may also be visible at the high end of the output voltage range. If both vapor phase and liquid phase peaks are present, the analysis program selects the threshold voltage $\left(V_{T}\right)$ at the midpoint between these peaks. If one of these peaks is absent, the analysis program first eliminates bins at high and low voltage extremes which contain fewer than 100 samples. This minimizes possible biasing due to the presence of a "tail" in the voltage histogram caused by spurious voltage spikes in the output signal. The threshold voltage is then taken as the median, i.e., midpoint between the highest and lowest voltage bins after the elimination process. This technique for determining the threshold voltage is somewhat arbitrary, since the actual residence time of liquid droplets at the HFA sensor is not known. However, the integrated averages of various HFA $Z$ scan data profiles obtained were found to be in good agreement with line-average gamma densitometer measurements under various adiabatic annular flow conditions.

In addition to the local void fraction, the data analysis program also provided a measurement of local liquid droplet frequency by counting the number of positive pulses in a known measurement time. This measurement is complicated due to the variable amplitude of the liquid droplet pulses, which results from different droplet sizes and eccentric droplet impaction on the HFA sensor. Although a few pulses extend above the threshold voltage level established for void fraction computation, some are of lower amplitude and extend a small amount beyond the random voltage fluctuations associated with the baseline voltage of the continuous vapor phase. If these droplets are not accounted for, a significant error results in the measured droplet frequency and in certain derived quantities such as droplet size. It is therefore necessary to establish a separate threshold voltage level for liquid droplet counting. In addition, it was also found that the signals needed to be digitized at a sampling rate of $50 \mathrm{kHz}$ to sufficiently resolve droplet impactions at high flow rate. The baseline vapor phase voltage is assumed to be well represented by a Gaussian distribution, as established from voltage data records obtained in pure liquid flow. 
Thus, the discrete voltage samples of the continuous vapor phase fall within the range $V_{\min }$ to $V_{\min }+2\left(V_{\text {peak }}-V_{\min }\right) ;$ the latter value is used as the threshold voltage for droplet frequency determination.

Knowing the droplet frequency $\left(f_{d}\right)$ and the droplet velocity $\left(V_{d}\right)$, a spherical equivalent diameter for the droplets can be derived as

$$
d_{d}=1.5 \frac{V_{d}(1-\alpha)}{f_{d}}
$$

where $\alpha$ and $f_{d}$ are measured by the upstream sensor of the HFA probe and the time-average liquid droplet velocity is obtained from the cross-correlation between the output voltage signals of the two sensors.

\section{Description of Vapor Turbulence Data Analysis}

As shown in Figure 3, a typical signal is characterized by a relatively low baseline voltage, indicative of the vapor phase, upon which are superimposed positive "spikes" produced by the dispersed droplet field. Analysis of such a signal for local void fraction and droplet frequency measurements in annular flows were described in the previous section. Additional analysis can provide local measurements of the mean and fluctuating vapor velocity, provided that the droplet pulses can be removed from the voltage record, and a calibration exists which relates the output voltage to the known vapor velocity. Both of these steps in the data analysis procedure are briefly discussed below.

The general form of the output voltage signal reported by previous researchers for gasparticle flows is essentially the same as that illustrated in Figure 3. Several methods have been proposed for eliminating the portion of the signal due to particle impingement on the HFA sensor, 
to enable calculation of gas phase turbulence statistics. For two-phase jet flows of cotton seed oil and air, Hetsroni et al. $(1969 ; 1971)$ used a voltage level thresholding method. Conversely, Ritsch and Davidson (1992) used a slope thresholding approach for duct flows of oleic acid particles in air.

Because the liquid droplet concentration encountered in the present experiments was higher than in some previous studies, a combined level and slope thresholding method was used. A similar approach was proposed by Lee (1982), and subsequently applied by Wang et al. (1990), for measurement of turbulence quantities in air-water bubbly flows. To directly apply this method in the droplet core of an annular flow field, the raw signal was first inverted, then the portion of the signal due to the droplets was removed using the algorithm of Lee, and then finally the data were inverted back to their original amplitude.

Because experiments were done in refrigerant $\mathrm{R}-134 \mathrm{a}$ vapor, which could not be readily seeded for simultaneous LDV measurements, no in-situ calibration could be performed to relate the single-phase vapor velocity to the output voltage of the HFA probe. Therefore, an alternative approach was required to estimate the vapor velocity from the existing data. To construct a calibration curve, it is assumed that the voltage at the center of the peak in the HFA output voltage histogram (Figure 4 ) is representative of the mean voltage in the continuous vapor phase. Also, it is assumed that at high local void fractions $(\alpha>0.9)$, the dispersed liquid droplets are transported at approximately the same velocity as the vapor. The implications of these assumptions are discussed in the following section.

\section{Measurement Uncertainty}

Total flow rate through the test section was maintained within $\pm 3 \%$ of the value specified, 
and was measured with at least $3 \%$ precision. The determination of the uncertainty for the hot film anemometry is based on the root-sum-square uncertainty interval for $95 \%$ confidence:

$$
U= \pm\left[B^{2}+\left(t_{95} S_{x}\right)^{2}\right]^{1 / 2}
$$

where $\mathrm{B}$ is the bias limit and $t_{95} S_{x}$ is the precision limit. The main sources of uncertainty considered in void fraction and droplet frequency measurements were repeatability based on pooled standard deviation, and the biases of threshold voltage, small droplets, position and sampling time, and droplet impaction. The uncertainty in void fraction was calculated to be \pm 0.025 . The uncertainty in frequency was somewhat higher with up to $25 \%$ for a mass flow rate of $106 \mathrm{~kg} / \mathrm{hr}$ and $14 \%$ for $532 \mathrm{~kg} / \mathrm{hr}$. The sources of uncertainty considered for droplet velocity measurements were repeatability, and the biases of velocity sampling, droplet size, crosscorrelation, sensor spacing and position. This uncertainty was calculated to be $7 \%$ for near wall measurements $(\mathrm{Z} / \mathrm{t}<0.2)$ and $6.4 \%$ for far wall measurements $(\mathrm{Z} / \mathrm{t}>0.2)$.

\section{Results and Discussion}

The experimental results provided here were obtained with a fixed nominal system pressure of $2.4 \mathrm{MPa}$. The two operating variables were mass flow rate $(106,266$ and $532 \mathrm{~kg} / \mathrm{hr})$ and cross-sectional average void fraction ( 0.77 and 0.92$)$. After establishing the pressure and the mass flow rate, the inlet heaters were used to generate the desired void fraction at a downstream location as measured by the gamma densitometer. The results in this section correspond to measurement profiles taken in the narrow Z-dimension of the test section.

The dispersed droplet velocities measured using the HFA cross-correlation technique were validated using the laser Doppler velocimeter, and the agreement between the two data sets was generally quite good. This comparison was discussed in a previous publication (Trabold et al., 
1998). The three probe calibration experiments were conducted at mass flow rates of $w=106,266$ and $532 \mathrm{~kg} / \mathrm{hr}$, and all with cross-sectional average void fractions of 0.92 or greater. The velocity data from these runs (for $\mathrm{Z} / \mathrm{t}>0.2$ ) were therefore used as the basis of the calibration curve illustrated in Figure 5 . These data are reasonably well represented by a second order polynomial, which is a form often used for HFA velocity measurements. To strengthen the argument that the vapor velocity and droplet velocity were approximately equivalent, the velocity calibration was determined by fitting a curve to only the centerline velocity data point for each of these runs, where the local void fraction was in excess of 0.96 and the calculated droplet sizes less than 0.12 mm. Further justification for this assumption is provided by invoking the separated flow model, for which it is assumed that all the liquid is moving at a single velocity and the vapor is moving at another velocity. The vapor velocity is represented by

$$
V_{g}=\frac{w x}{A \rho_{g} \alpha}
$$

where $x, A, \rho_{g}$ and $\alpha$ are quality, duct cross-sectional area, vapor density and average void fraction. For the calibration experiments conducted at 106,266 and $532 \mathrm{~kg} / \mathrm{hr}$, the vapor velocity calculated by Equation (3) is $1.2,3.0$ and $5.3 \mathrm{~m} / \mathrm{s}$, respectively. These values compare well with the integrated averages of the dispersed droplet velocity distributions across the Z-dimension [see insets of Figure 5]. These velocity profiles are parabolic and show that the bigger droplets near the wall drag the flow near the wavy interface, resulting in lower velocity.

In Figure 6, the data are replotted to understand the relationship between droplet diameter and velocity. Droplet velocities normalized in terms of two-phase mixture velocity are plotted as a function of droplet diameters normalized by the hydraulic diameter. Mixture velocity is given by 


$$
V_{m}=\frac{G}{\rho_{2 \phi}} \text { where } \rho_{2 \phi}=\rho_{g} \alpha+\rho_{l}(1-\alpha)
$$

In general, for high void fractions, the droplet velocity is approximately the same as the mixture velocity. At lower void fractions, particularly for low flows, the droplet velocity tends to be higher than the mixture velocity because the mixture velocity calculation includes a larger percentage of the film mass flux, and the film travels at a significantly lower velocity than the gas core.

With a calibration curve established which relates output voltage to velocity, it is possible to calculate the vapor velocity and turbulence intensity for any test condition, provided that the operating resistance of the probe is held constant at the value used in the calibration. For each voltage sample, the velocity is calculated via the calibration curve and the turbulence intensity is the root-mean-square of the differences between each velocity sample and the mean velocity.

The three conditions for which turbulence data are reported were chosen such that annular flow was maintained for two void fractions at the same mass flow rate $(w=106 \mathrm{~kg} / \mathrm{hr})$, and the flow rate was varied at the same high void fraction $(\alpha=0.92)$. Measurements are not presented for $w=532 \mathrm{~kg} / \mathrm{hr}$, due to the very high droplet concentration which made it difficult to extract a sufficient continuous vapor phase voltage record.

The void fraction profiles are presented in Figure 7. Although it is difficult to infer the average film thickness, it is clear that for $w=106 \mathrm{~kg} / \mathrm{hr}$, the wave roughness on the base film can extend to about one-fourth of the test section thickness for $\alpha=0.77$, and about one-tenth for $\alpha=$ 0.92. A slight inversion in the void fraction is seen for the high flow case. Figure 8 shows the droplet frequency profiles for the same three flow conditions. The frequencies are nearly the same for the two low flow conditions with a slight increase toward the test section center. However, for the high flow, the frequencies are an order of magnitude higher than for the low flow cases. This 
suggests that the vapor core turbulence plays a significant role in breaking up the droplets and increasing the concentration for approximately the same volume fraction of the dispersed droplet phase.

In Figure 9, droplet diameter non-dimensionalized by a turbulent length scale is plotted against the non-dimensionalized distance from the wall. This characteristic length scale of the energy-containing eddies was taken as 0.2 times the hydraulic radius as suggested by Hutchinson et al. (1971). They used a lower value of 0.05 times the tube radius near the wall, but in the current study a uniform value of 0.2 has been used. The length scale of Hutchinson et al. was also used by Azzopardi and Teixeira (1994a; b) and Hetsroni (1989). As expected, the droplet diameter given in Figure 9 is high for $\alpha=0.77$ compared to $\alpha=0.77$. At this low void fraction, the entrainment is high since the wave roughness is large (as implied by the data in Figure 7) and the drop diameter tends to be large. Near the wave surface, the diameters are measured to be approximately $0.75 \mathrm{~mm}$, a significant fraction of the test section thickness $(t)$, especially given that the film thickness on both walls is expected to be a large fraction of the test section dimensions as well. Despite the scatter in the drop diameter for this void fraction, there is a decreasing trend in the drop size from the wave surface to the center of the test section. The droplet diameter stays nearly constant for $\alpha=0.92$ for both low and high flows and is an order of magnitude smaller than the low void case. There is a slight trend for the high flow to have slightly larger diameters near the test section center compared to close to the waves. This is consistent with our observations in Figure 7 of a slight void inversion for this case. It is possible that the larger drops for this flow condition are generated from the waves at the two edges of the duct rather than from the flat walls.

The vapor core turbulence intensity (i.e., the root-mean-square velocity fluctuation 
normalized with the local mean velocity) is provided in Figure 10. The turbulence intensity is maximum near the interface and drops near the center of the duct, almost aligned with the droplet diameter profiles for each flow condition. The turbulence intensity decreases with increasing void fraction and increasing flow rate. It has been reported previously that turbulence is enhanced due to an increase in drop size as well droplet concentration (Hewitt and Govan, 1990). The present results suggest that the drop size has a more significant effect on turbulence than droplet concentration. Even as the droplet frequency increases by more than an order of magnitude upon increasing the mass flow rate from 106 to $266 \mathrm{~kg} / \mathrm{hr}$ for $\alpha=0.92$ (Figure 8), the higher flow rate has the lowest turbulence intensity as seen in Figure 10 because the droplets are smaller. For $\alpha=$ 0.92 , the drop sizes for these two flow rates is in the range of 0.05 to $0.1 \mathrm{~mm}$ in diameter, and the turbulence intensity is nearly the same in the vapor core away from the interface. However, the turbulence intensity is much higher near the liquid film interface $(Z / t=0.06$ to 0.2$)$ for $w=106 \mathrm{~kg} /$ $\mathrm{hr}$ and $\alpha=0.92$. At this flow condition, the contribution to the turbulence intensity is not solely from the droplet field, but also from the waviness of the interface. This adds credence to the fact that the waviness increases interfacial shear in annular flow through the enhancement of turbulence in the vapor core. Indeed, the location at which droplet sampling and turbulence measurements are made in the vapor core is very important for validating different models. The only known published measurements of continuous vapor turbulence in gas-liquid annular flow are those of Azzopardi and Teixeira (1994b). These authors used laser anemometry techniques to measure the droplet and vapor velocities in air-water flows through a vertical $32 \mathrm{~mm}$ ID pipe. The air was seeded with $1 \mu \mathrm{m}$ polystyrene spheres which acted as light scattering particles. To compare these data with the present results, it is appropriate to plot the turbulence intensity against the drop size, especially in light of the significant effect of droplet diameter on 
the turbulence data illustrated in Figure 10. Also, to account for duct geometry, Azzopardi and Teixeira recommended normalizing the droplet size with the turbulent length scale. As was done in Figure 9, a characteristic length scale of 0.2 times the duct radius was used to normalize the droplet diameter data. By presenting the data in this manner, there appears to be close agreement between the trend in the present turbulence intensity results and those of Azzopardi and Teixeira (1994b), as illustrated in Figure 11.

\section{Summary and Conclusion}

A traversing two-sensor hot film anemometer technique was used in a heated refrigerant fluid system to make detailed measurements of void fraction, droplet frequency and droplet velocity in a narrow, high aspect ratio duct. In addition to these measurements, the sphericalequivalent droplet diameter was inferred from the void fraction, droplet frequency and velocity, and turbulence intensity was measured in the presence of liquid films on the wall. Such measurements are scarce in the literature, particularly for heated systems where the liquid-tovapor density ratio is low and comparable to steam-water systems at high pressures. The results presented in this paper provide evidence of the capability of the hot-film anemometer technique to acquire detailed local vapor turbulence data in annular refrigerant two-phase flow.

Turbulence intensity was favorably compared with data in the literature (Azzopardi and Teixeira, 1994b). Turbulence intensity was seen to be always enhanced for all drop sizes in annular flows, as opposed to what was observed in particle-laden flows in the literature. In particle-laden flows, particle size is known a priori, whereas in the current annular flow, the droplets are created by the shearing of the roll waves, and are not known a priori. The droplet diameters for the same flow rate but lower void fraction are seen to be an order of magnitude higher, and consequently, the turbulence intensity for this same flow is an order of magnitude 
higher as well. Secondly, the turbulence was seen to be enhanced not only due to the vortex motion behind larger drops but also due to the wave motion. Finally, the current experiments also show that the drop size has a more significant effect on the turbulence intensity than the droplet concentration, contrary to Hewitt and Govan's (1990) observation in air-water systems.

To improve the confidence in the technique and reduce the measurement uncertainty, particular attention should be devoted to improving the calibration procedure and obtaining direct measurements of droplet size and concentration using a digital image processing system.

Experiments should also be conducted to ascertain the effects of mass flow rate, pressure and wall heat flux on vapor core turbulence. 


\section{References}

Azzopardi, B.J. and Teixeira, J.C.F. (1994a) "Detailed Measurements of Vertical Annular TwoPhase Flow - Part I: Drop Velocities and Sizes," ASME J. Fluids Eng., Vol 116, pp. 792-795.

Azzopardi, B.J. and Teixeira, J.C.F. (1994b) "Detailed Measurements of Vertical Annular TwoPhase Flow - Part II: Gas Core Turbulence,” ASME J. Fluids Eng., Vol 116, pp. 796-800.

Carvalho, R. and Bergles, A.E. (1992) "The Pool Nucleate Boiling and Critical Heat Flux of Vertically Oriented, Small Heaters Boiling on One Side," Rensselaer Polytechnic Institute, Heat Transfer Laboratory Report HTL-12.

Faeth, G.M. (1983) "The Evaporation and Combustion of Sprays," Prog. Energy Combust. Sci., Vol. 9, pp. 1-76.

Faeth, G.M. (1987) "Mixing, Transport and Combustion in Sprays," Prog. Energy Combust. Sci., Vol. 13, pp. 293-345.

Franz, K., Borner, T., Kantorek, H.J. and Buchholz, R. (1984) "Flow Structures in Bubble Columns," Ger. Chem. Eng., Vol. 7, pp. 365-374.

Ginzburg, T. (1971) "Droplet Transport in Turbulent Pipe Flow," Argonne National Laboratory Report ANL-7694.

Goldschmidt, V.W. and Householder, M.K., "The Hot Wire Anemometer as an Aerosol Droplet Size Sampler," Atmospheric Environment, Vol. 3, pp. 643-651 (1969).

Hetsroni, G. (1989) "Particles-Turbulence Interaction," Int. J. Multiphase Flow," Vol. 15, No.5, pp. $735-746$.

Hetsroni, G., Cuttler, J.M. and Sokolov, M. (1969) "Measurements of Velocity and Droplet Concentration in Two-Phase Flows," Transactions of the ASME, Series E, Vol. 36, pp. 334-335.

Hetsroni, G. and Sokolov, M. (1971) “Distribution of Mass, Velocity, and Intensity of Turbulence in a Two-Phase Turbulent Jet," ASME J. Applied Mech., Vol. 12, pp. 315-327.

Hewitt, G.F. and Govan, A.H. (1990) "Phenomena and Prediction in Annular Two-Phase Flow," ASME FED-Vol. 99, Advances in Gas-Liquid Flows, J.H. Kim et al. (eds.).

Hogsett, S. and Ishii, M. (1997) "Local Two-Phase Flow Measurements Using Sensor Techniques," Nucl. Eng. Design, Vol. 175, pp. 15-24.

Hutchinson, P., Hewitt, G.F. and Dukler, A.E. (1971) "Deposition of Liquid or Solid Dispersion from Turbulent Gas Streams: A Stochastic Model,” Chem. Eng. Sci., Vol. 26, pp. 419-439. 
Lance, M and Bataille, J. (1991) "Turbulence in the Liquid Phase of a Uniform Bubbly Air-Water Flow," J. Fluid Mech., Vol. 222, pp. 95-118.

Lee, S.J. (1982) "The Development of a Digital Data Processing System for Two-Phase Turbulence Data," M.S. Thesis, Rensselaer Polytechnic Institute, Troy, NY.

Lee, S.L., and Durst, F. (1982) "On the Motion of Particles in Turbulent Duct Flow," Int. J. Multiphase Flow, Vol. 8, pp. 125-146.

Mahler, D.S. and Magnus, D.E., "Hot-Wire Technique for Droplet Measurements," Liquid Particle Size Measurements, ASTM STP 848, J.M. Tishkoff et al. (eds.), American Society for Testing and Materials, pp. 153-165 (1984).

Michiyoshi, I. and Serizawa, A. (1986) "Turbulence in Two-Phase Bubbly Flow," Nucl. Eng. Design, Vol. 95, pp. 253-267.

Ritsch, M.L. and Davidson, J.H. (1992) "Phase Discrimination in Gas-Particle Flows Using Thermal Anemometry," ASME J. Fluids Eng., Vol. 114, pp. 692-694.

Serizawa, A., Kataoka, I and Michiyoshi, I. (1975) “Turbulence Structure of Air-Water Bubbly Flow," Int. J. Multiphase Flow, Vol. 2, pp. 221-259.

Suzanne, C., Ellingsen, K., Risso, F and Roig, V. (1997) "Local Measurements in Turbulent Bubbly Flows," Proc. of the OECD/CSNI Specialist Meeting on Advanced Instrumentation and Measurement Techniques, Santa Barbara, California.

Trabold, T.A., Moore, W.E., Morris, W.O., Symolon, P.D., Vassallo, P.F. and Kirouac, G.J., “Two Phase Flow of Freon in a Vertical Rectangular Duct. Part II: Local Void Fraction and Bubble Size Measurements," Experimental and Computational Aspects of Validation of Multiphase Flow CFD Codes, I. Celik et al. (Ed.), FED-Vol. 180, pp. 67-76, ASME (1994).

Trabold, T.A., Moore, W.E. and Morris, W.O. (1997) "Hot-Film Anemometer Measurements in Adiabatic Two-Phase Refrigerant Flow through a Vertical Duct," ASME Fluids Engineering Division Summer Meeting, Vancouver, B.C., Paper FED SM97-3518.

Trabold, T.A., Kumar, R. and Vassallo, P.F. (1998) "Annular Flow of R-134a in a Vertical Duct: Local Void Fraction, Droplet Velocity and Droplet Size Measurements," accepted for presentation at IMECE'98, ASME, Anaheim, CA.

Tsuji, Y. and Morikawa, Y. (1982) "LDV Measurements of an Air-Solid Two-Phase Flow in a Horizontal Pipe,” J. Fluid Mech. Vol. 120, pp. 385-409.

Tsuji, Y. and Morikawa, Y., and Shiomi, H. (1984) "LDV Measurements of an Air-Solid TwoPhase Flow in a Vertical Pipe," J. Fluid Mech. Vol. 139, pp. 417-434. 
Ueda, T. (1979) "On the Droplets Entrained in Two-Phase Annular and Mist Flow," Two-Phase Flow Dynamics, Japan-U.S. Seminar, A.E. Bergles and S. Ishigai (Eds.).

Wang, S.K., Lee, S.J., Jones, O.C. and Lahey, R.T. (1990) "Statistical Analysis of Turbulent TwoPhase Pipe Flow," ASME J. Fluids Eng., Vol. 112, pp. 89-95. 


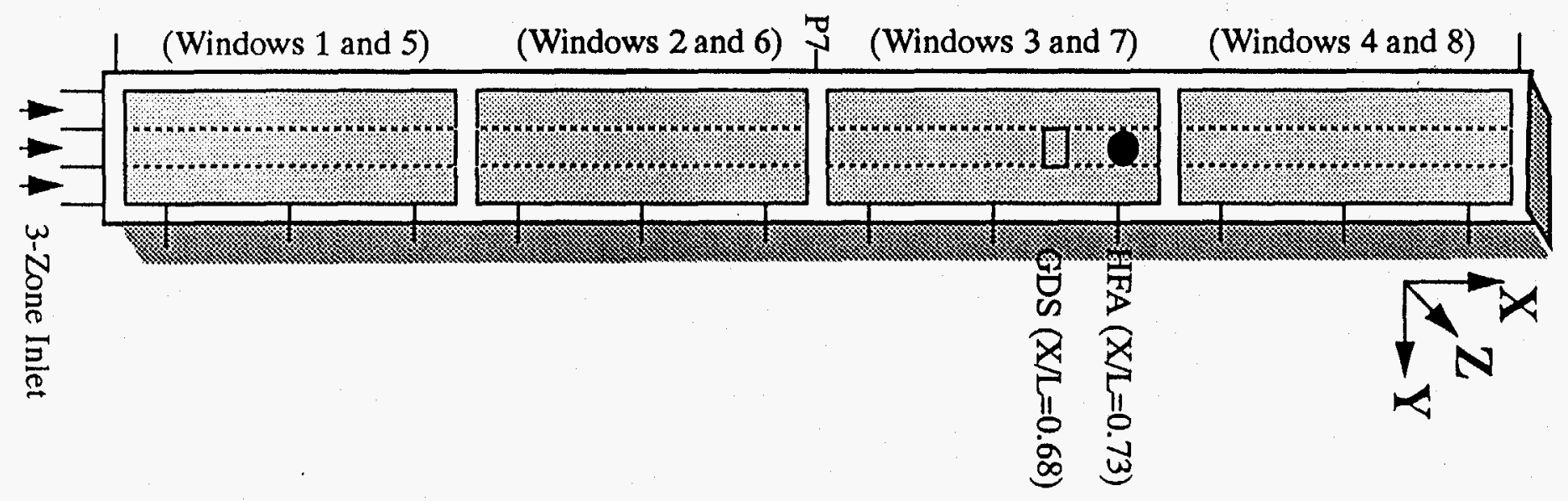




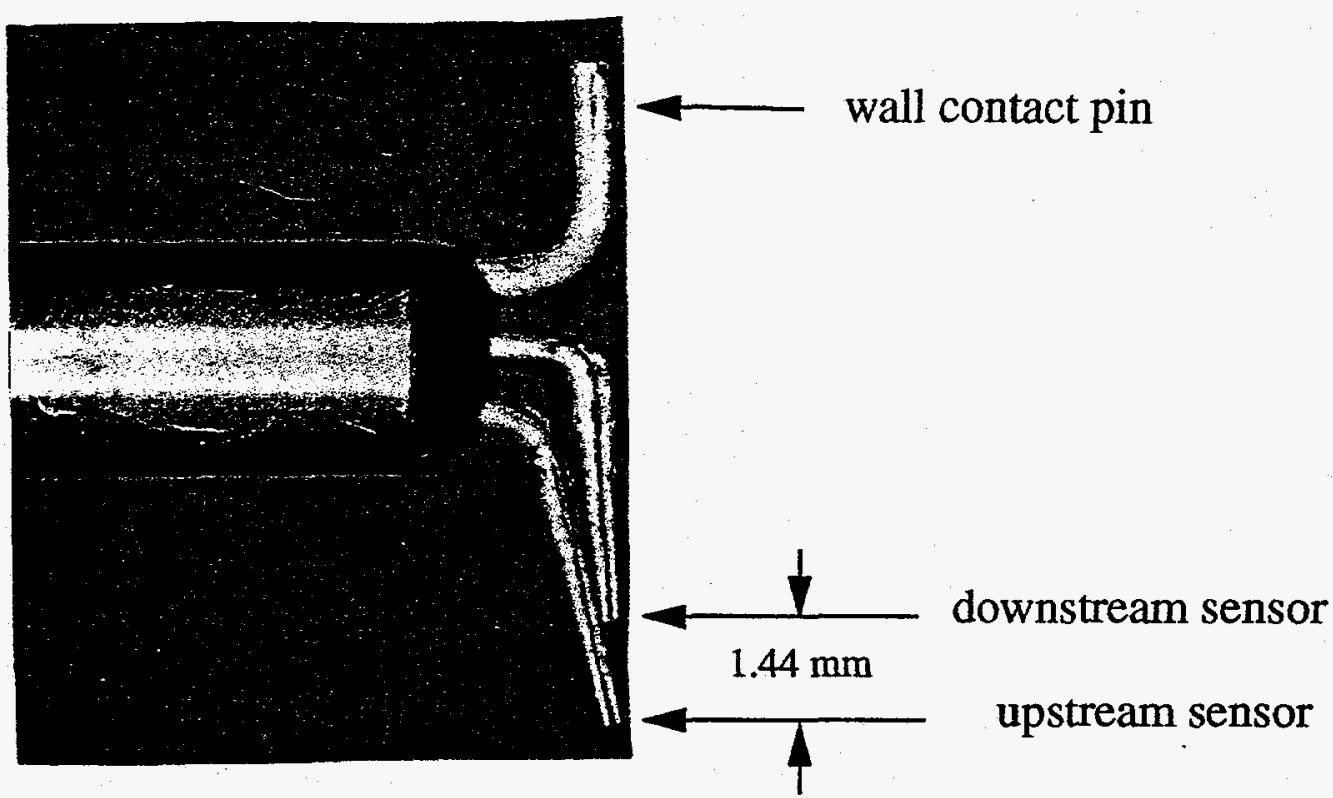

Figure 2 - Photograph of Dual-Sensor HFA Probe (7.5X magnification) 


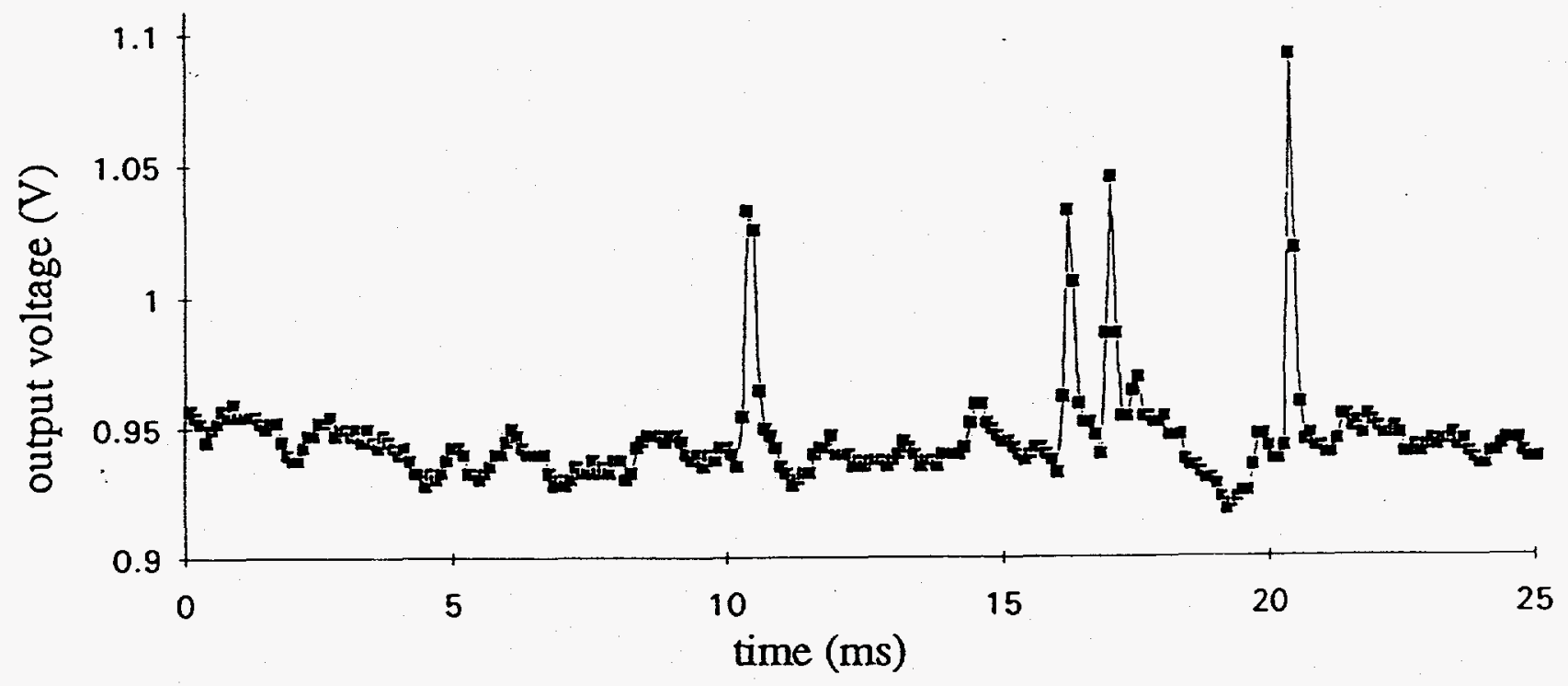

Figure 3 - HFA Output Voltage Signal in Vapor Core of Annular Flow 


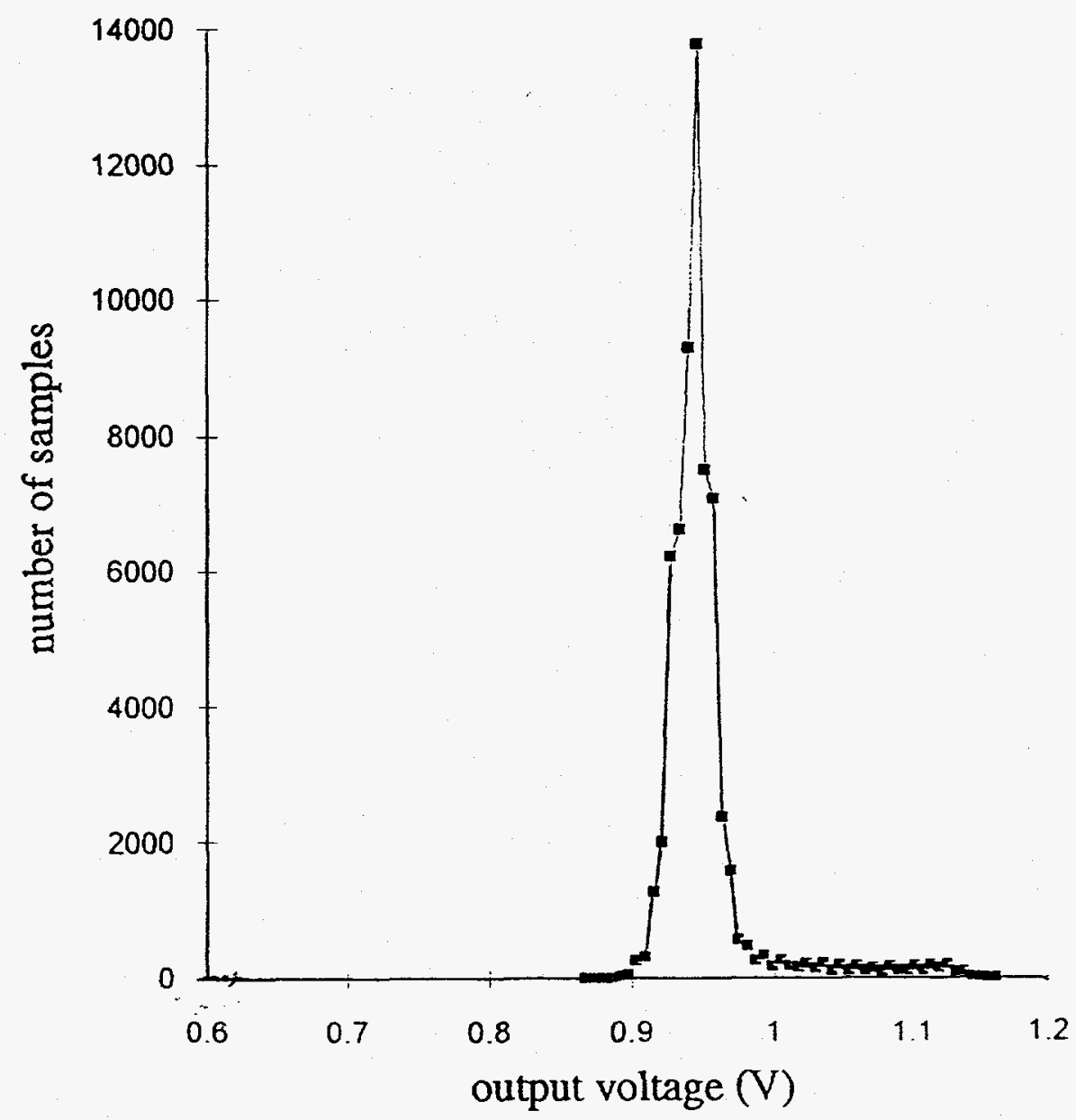

Figure 4 - Voltage Histogram for HFA Signal in Vapor Core 


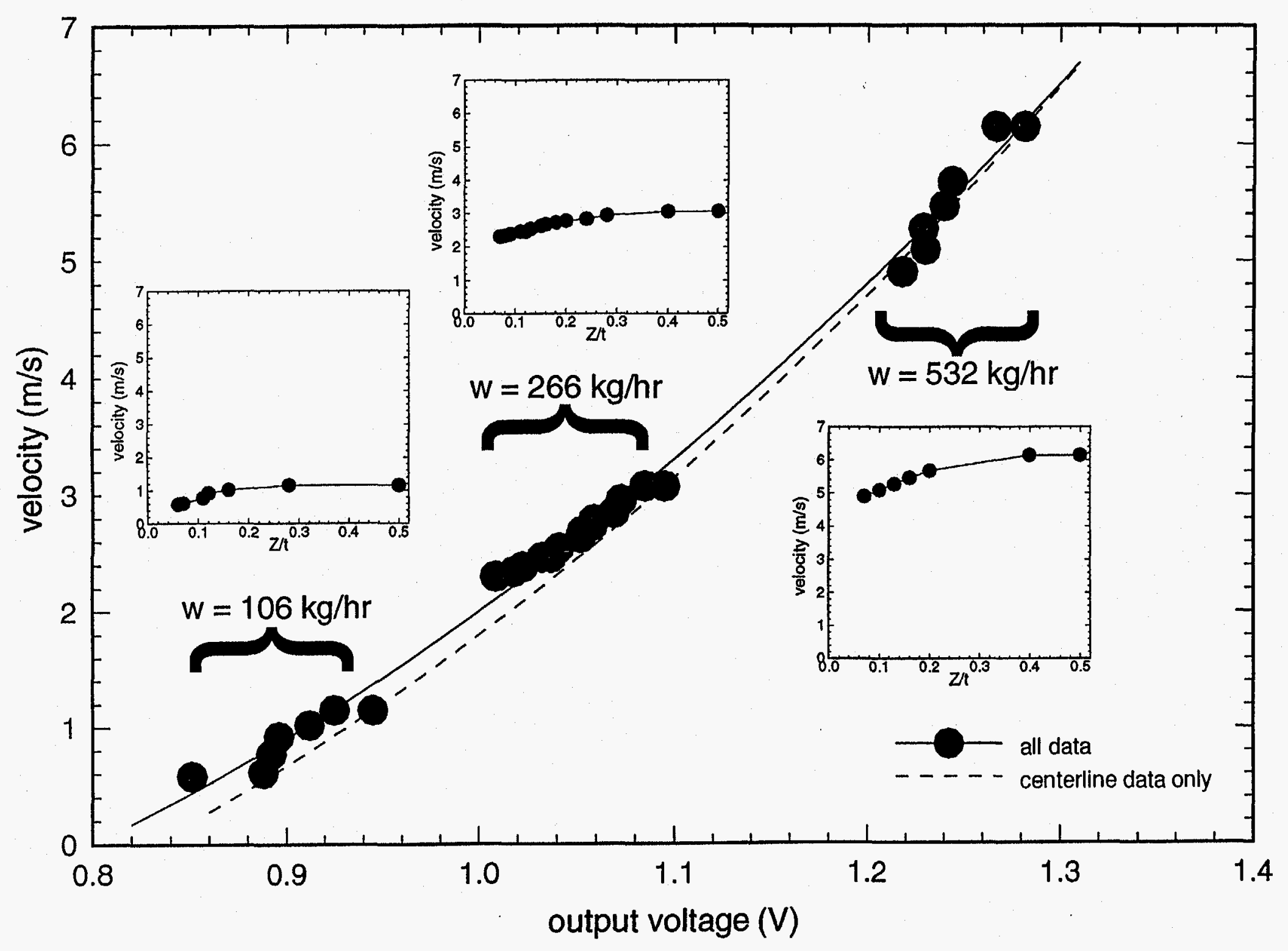

Figure 5 - HFA Velocity Calibration Curve 


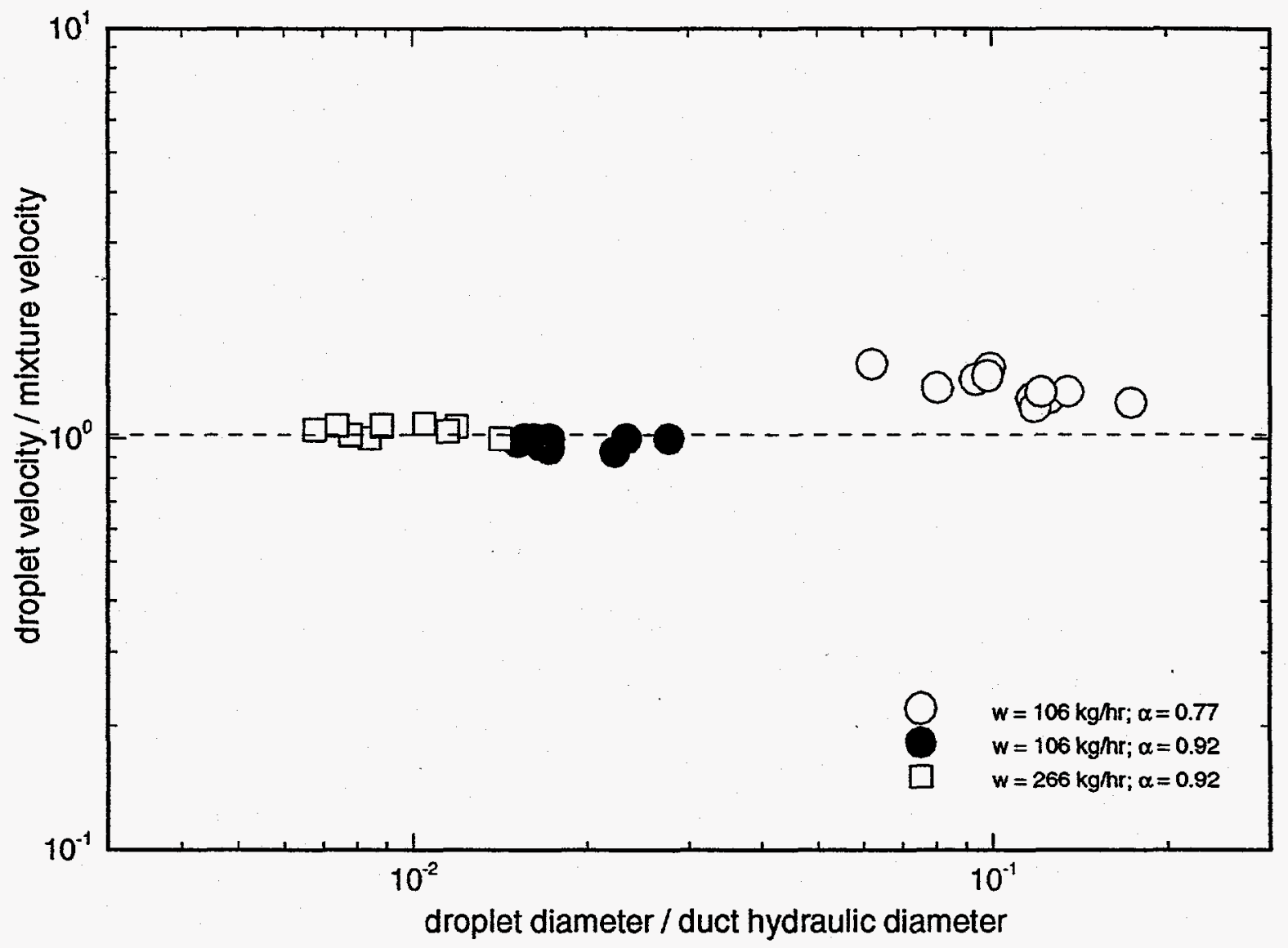

Figure 6 - Relationship Between Dimensionless Droplet Diameter and Velocity 


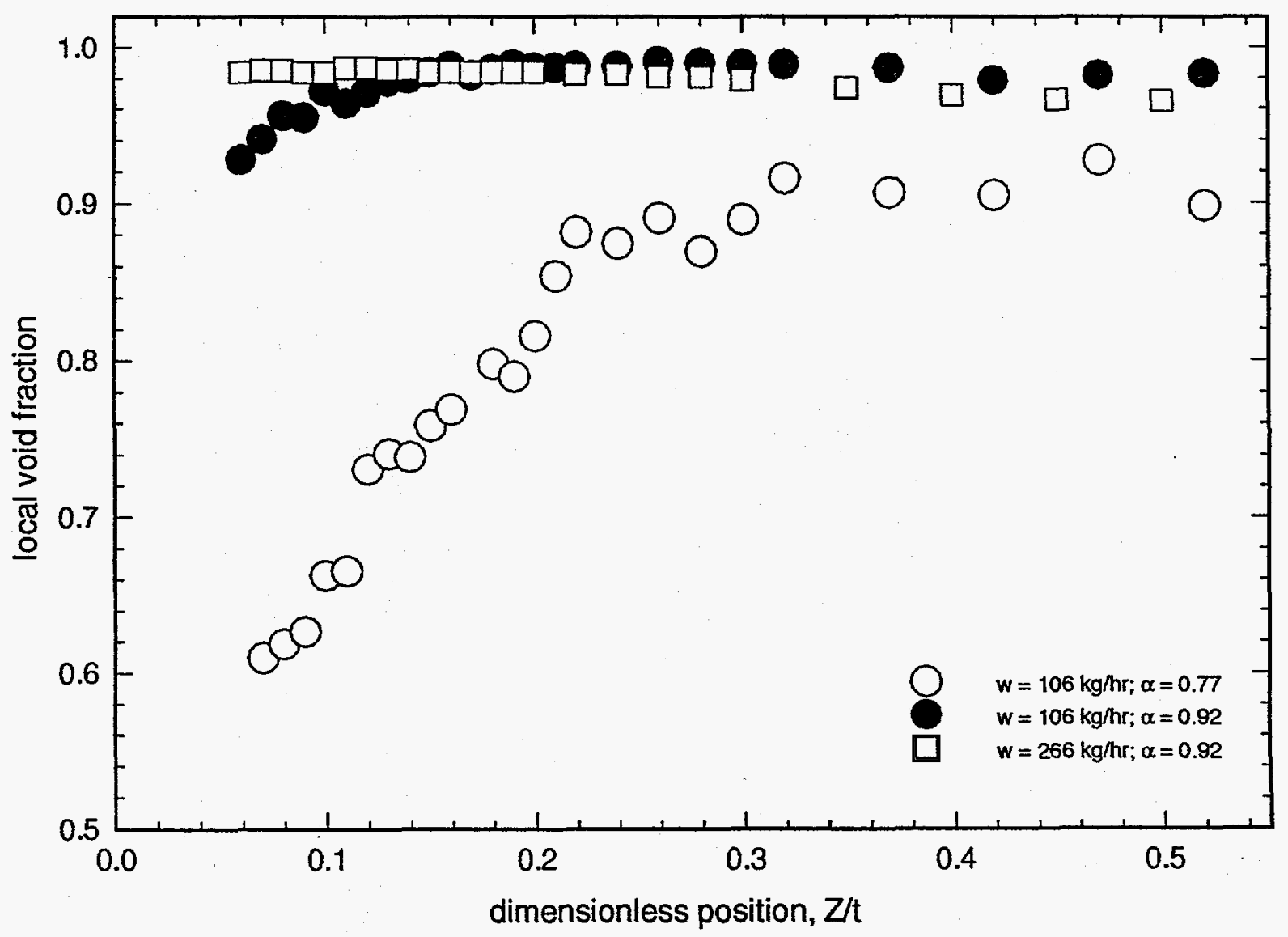

Figure 7 - Local Void Fraction Distributions 


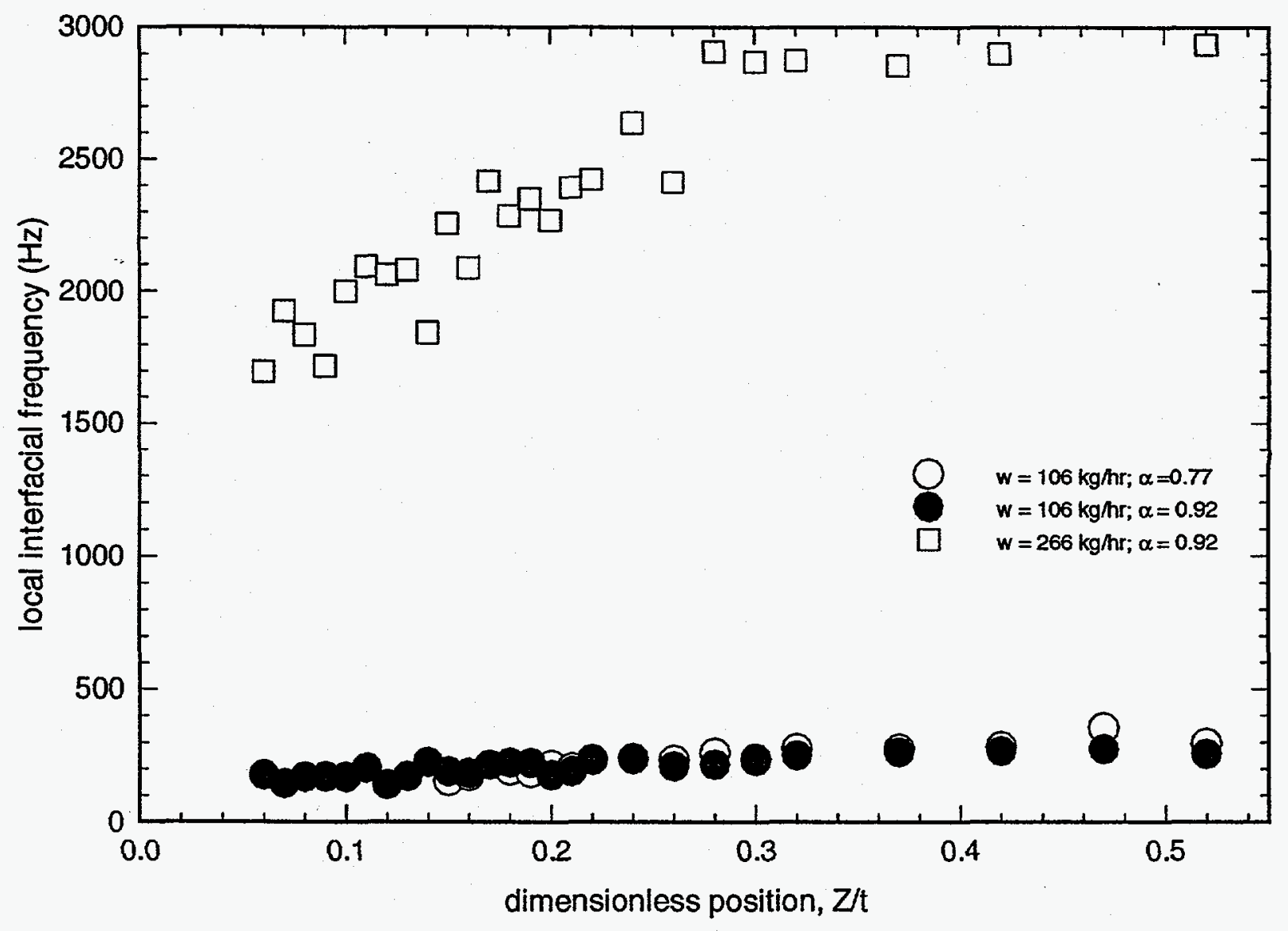

Figure 8- Local Interfacial Frequency Distributions 


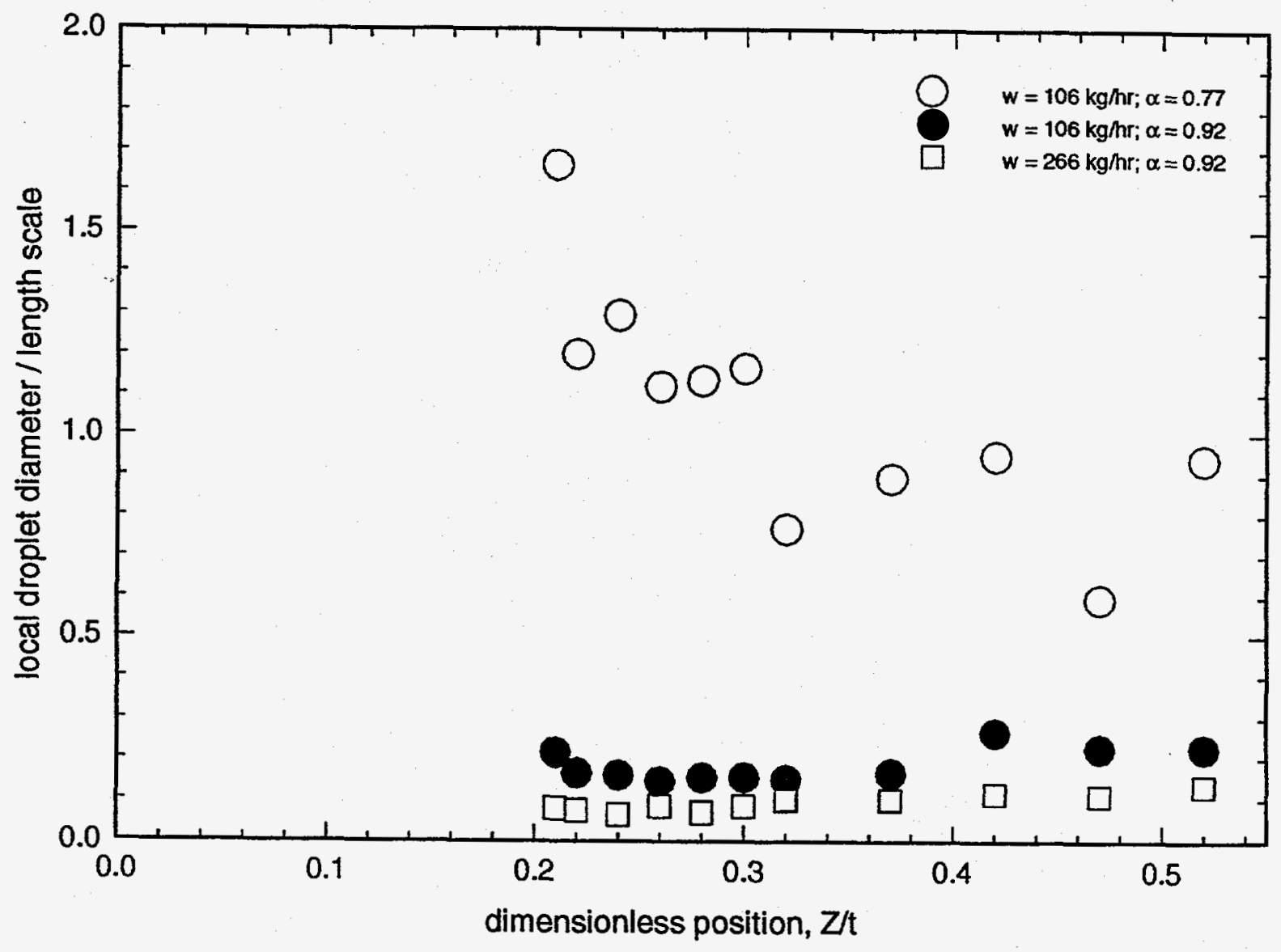

Figure 9 - Local Dimensionless Droplet Diameter Distributions 


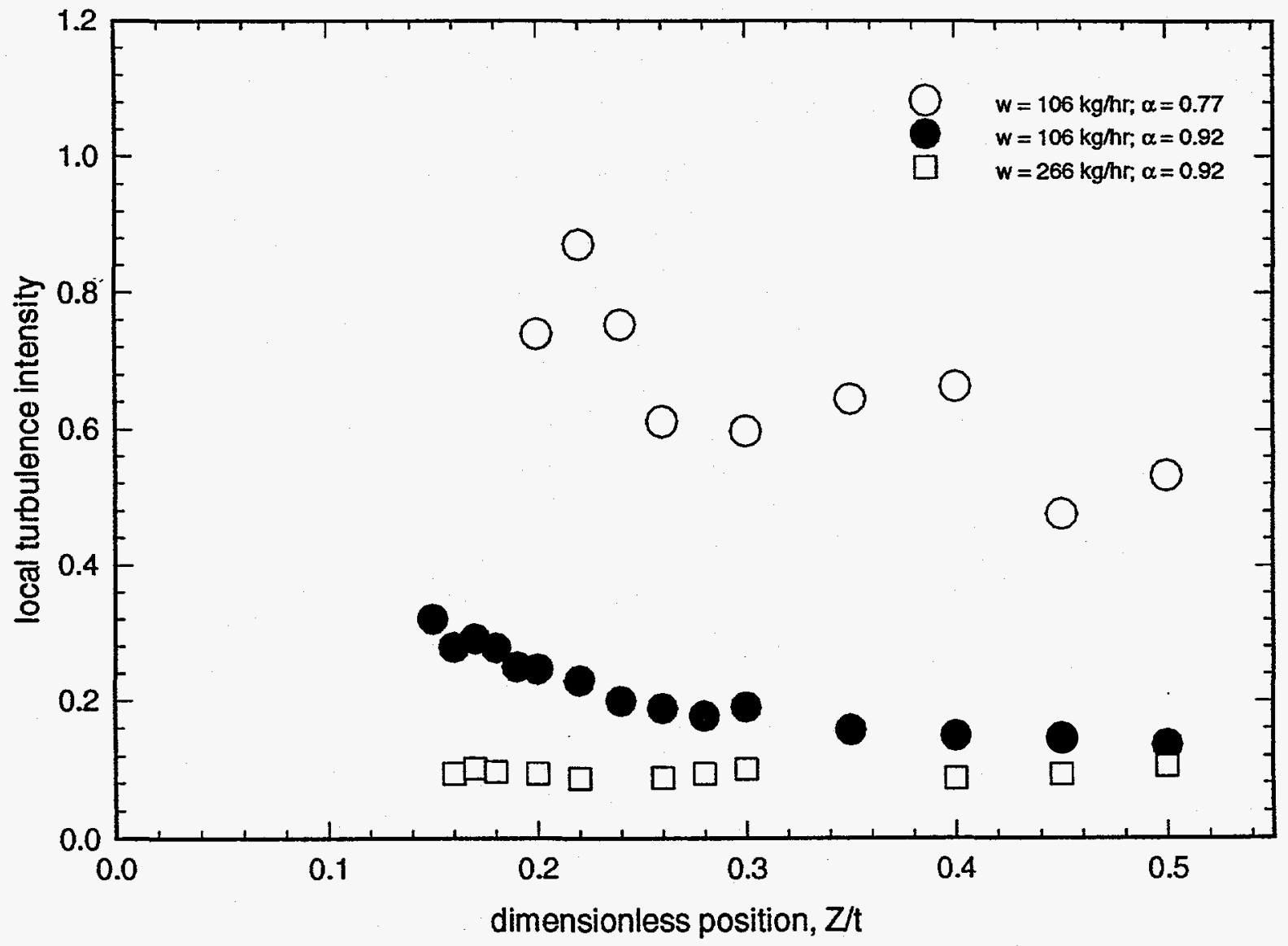

Figure 10 - Local Turbulence Intensity Distributions 


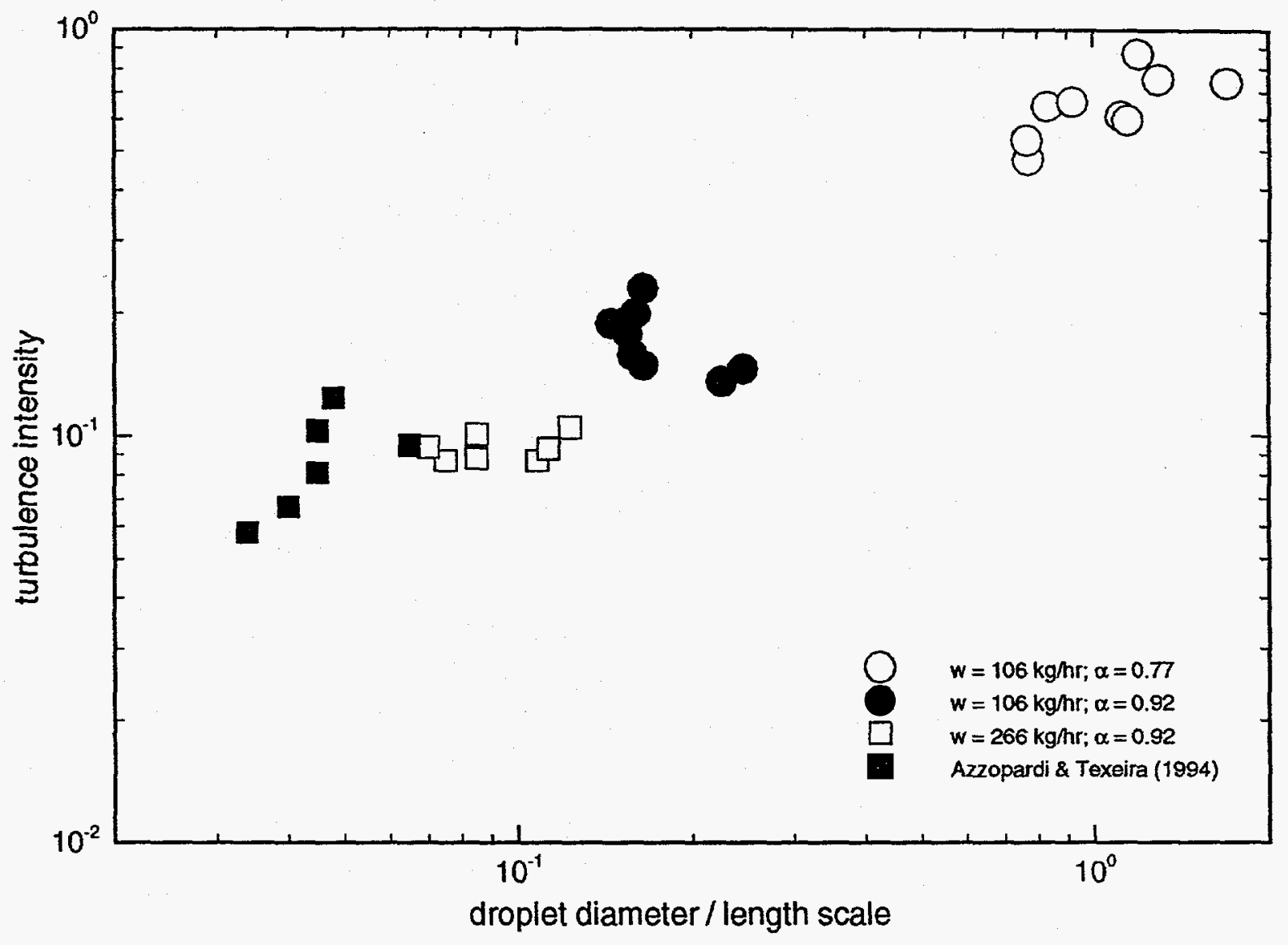

Figure 11 - Relationship Between Dimensionless Droplet Diameter and Turbulence Intensity 